\title{
A Supply Chain Risk Index Estimation Methodological Framework Using Exposure Assessment
}

\author{
Arij lahmar ${ }^{1,2}$, François Galasso ${ }^{2}$, Habib Chabchoub ${ }^{1}$ and Jacques Lamothe ${ }^{2}$ \\ ${ }^{1}$ Unit of Logistic, Industrial and Quality Management (LOGIQ) \\ University Of Sfax, Faculty Of Economics Sciences and Management \\ Sfax, Tunisia Arij.lahmar@hotmail.fr, \\ ${ }^{2}$ Industrial Engineering Center (CGI), University of Toulouse, Mines Albi \\ Campus Jarlard - 81013 ALBI, France \\ \{francois.galasso, jacques.lamothe\}@mines-albi.fr
}

\begin{abstract}
The objective of this article is to move a step forward towards the general knowledge about how to manage supply chain risks by developing a theoretical risk index using exposure analysis. Two questions "why logistics systems are exposed to risks? to which type of risk, a supply chain organization is exposed to?" have to be raised and investigated. The answers to these questions will be used as a basis for the risk index methodology, which allows organizations to assess their exposure level and also to identify which type of risk they need to deal with it. The results of previous step will be computed into a supply chain risk index. To achieve our objective, the article is organized as follows: section 2 provides a brief literature review to position the proposed model against other existing theoretical models. Section 3 provides the methodology used to develop our approach. Section 4 presents the conclusion, limitations and future research.

Keywords: supply chain risk, exposure supply chain trends, probability of occurrence, disruptive events, hazard.
\end{abstract}

\section{Introduction}

According to [1], different types of disruptions are threaten supply chain causing several financial losses. Thus protecting supply chains and making them less vulnerable to different types of disruptions have become one of the main priorities for both researchers [5-10] and practitioners (Resilience Report 2012, 2013 and 2015, Generix Group 2015, Accenture 2014, etc.), where there is a common consensus about the need to determine the causing factors of supply chain susceptibility to risks and the their occurrence impacts [1-4]. The attempts to give answers to these basic questions have been the topic of years of research and experiments, resulting in a plethora of tools, methods and practices that deal with different issues related to supply chain risks [3]. The need for an effective approach to manage supply chain risks seems apparent. [11-14] highlight that the search for a mitigation strategy or solution required first and foremost a clear understanding of what the supply chain risk concept means, which still missing in the literature review [3][14]. According to the authors, "the real challenge in the field of supply chain risk management is still the quantification and 
modeling of supply chain risk". For instance, [16-17] characterize supply chain risk by the combination of three terms: consequence, vulnerability and disruptive events; where consequence is the maximum possible loss, vulnerability is the potential exposure of supply chain to potential disruptive events scenarios and disruptive event is the possibility of occurrence per time frame. Moreover, [18] highlight the important for of disruptions detection for defining effective risk management practices. Following the same line of thinking, [19] emphasize the significance of disruption detection using a manufacturer case study by integrating this dimension, "detection" into occurrence models to calculate the duration of a risk event. The results of this study prove that in large supply chains it may be challenging to detect the occurrence of a risk event. According to this study, it had taken the manufacturer several weeks to discover the source of the disruptions and to estimate their likelihood and their impacts, which resulted in a loss of market share to competitors. As a result, the authors suggest that academics and practitioners need to invest more in discovering and developing more appropriate dimensions to assess supply chain risks and to develop new approaches to manage the critical risks [20]. Although that the domain of supply chain risk management extend to 30 years, the quantification and computation frameworks of supply chain risk are just beginning to emerge and more research progress is expected to be made in the future research[21]. [22-25] believe that supply chain characteristics need to be considered when assessing and measuring supply chain risks to guarantee the accuracy of developed risk measurement methods. [26] underline that risk cannot be measured without taking into account the supply chain exposure level and the safety measures applied. And these latter are changeable and depend on both risk type and supply chain characteristics. [27] suggest that identifying risk factors and most exposed or vulnerable component within supply chain is a crucial sub-problem of a general risk management process. Therefore, there is a need for additional analysis of causing path of supply chain risks to capture the impact of supply chain on risk dimensions.

Informed by the above critical aspects of this issue, this article proposes an comprehensive essay to estimate supply chain risk occurrence based on exposure analysis. We extend the general risk quantification model to propose a broader quantification approach focusing on probability perspective. We assume that supply chain risk is defined with regard to two perspectives, the causal aspect and the consequence one. In this article, we focus on the causality perspective of supply chain risks: How supply chain risk is generated? and we model Risk probability as a function of exposure factors and the occurrence of one or a set of disruptive events.

To reveal the reasons and to describe the method to incorporate exposure factors into the probability quantification of supply chain risk formula, this paper is organized as follows: after the introduction, section 2 presents an overview of the most common frameworks of supply chain risks from the probability perspective. Section 3 discusses a conceptual model to include exposure in the supply chain risk occurrence analysis. Section 4 details the conclusions, limitations, and future directions regarding our conceptual model. 


\section{Research Background}

According to [28-30], a huge variety of works with diversified themes and approaches have been developed to define supply chain risks. And this can be explained by the nature of risk that is inherent from the concept of life. It implicitly reflects the complexity, instability and diversity of managerial interactions. As a result, no universally accepted definition of supply chain risk exists [31-32]. However, whereas specific definitions of risk might vary, a few characteristics are common to all definitions, which are : the probability of occurrence of a particular disruptive event, hazard or negative outcome and the consequence of the particular disruptive event, hazard or negative outcome if it is occurring. [33] confirm that risk management strategy or method needs to address all three dimensions to effectively manage supply chain risk. This could explain why $67 \%$ scientific articles define supply chain risk as a measure of the likelihood (probability) that unexpected disruptive event(s) will cause negatives impacts or losses to supply chain performance [13]. Different terms are often used synonymously to refer to these events, such as risk drivers, risk trigger, hazard, risk sources [38], disturbance or conditions that leads to the occurrence of a risk. To avoid confusion in the terminologies used, "disruptive event" will be used for the rest of this article. These events could be considered as one of the characteristics of the underlying supply chain as well as an external driver from supply chain environment. The likelihood of a disruptive event is specified by the probability of occurrence, which has been considered as the central aspect of risk perception in most research areas and the core of various definitions developed in the context of supply chain risk management [3]. Thus assessing supply chain risks consequences merely requires the definition of the disruptive events occurrence and then, the estimation of their occurrence probability and then their possible effect on supply chain objectives [34-35]. However, these events have been always considered as distinct from the characteristics of supply chain although that [21] and [24] highlight the need to consider these characteristics when modeling and assessing supply chain risk. To summarize, all previous frameworks have often attach slightly different meanings of supply chain risk upon the context in which it is viewed [1213]. The notion of explicitly establishing the context in which supply chain risk is evaluated to ensure that appropriate measures and interpretations are made. This context is referred to it as exposure factors. There is a need to understand the causal factors leading to the occurrence of Supply Chain Risk, related to the identification and the estimation of trigging events and the manner in which they lead to different types of risks. In order to address the problematic identified, a general theoretical risk exposure estimation model is developed in section 3 .

\section{Research Methodology}

The results of the previous section emphasis that events are one of the important ingredients to understand the occurrence process. However, the transformation mechanisms of these events to potential supply chain risks is missing in the literature review. Probability of disruptive events (fire, natural disasters, etc) is a risk metric 
that only quantifies uncertainty. It does not address the supply chain exposure to these events and its consequences, which depends upon the extent to which a supply chain is susceptible to a specific or unspecific risk events. These hazardous events may be potentially harmful to supply chain process, activities, flows, and organizations but also to the entire network, which are all grouped together under the term Elements-atrisk or assets. According to the survey's results published by [39-40] the frequency of the disruptive events is increasing. The results have underlined that there is nearly 1500 disruptive events threaten supply chain each year [40. pp.3-4] and $49.9 \%$ of companies have experienced supply chain disruptive events during 2016. These statistics prove that not all supply chain organisations are exposed neither to the same level and nor to the same type of disruptive events. As a result, it is becomes crucial for a company to determine whether it is truly exposed to any of the possible risks or hazards that exist. It becomes important to know whether its perception of exposure is adequate with the risk level (sets of likelihoods multiplied by impacts) that can be anticipated. As organizations are not vulnerable to every possible risk that may exist, it is a real concern to be able to define the level of risk susceptibility or exposure. The ability to deal with (and over time adapt to) various risk factors is an important element for continued existence, placed after their possibility of detection and evaluation. As a result, exposure to risk has been highlighted by several researchers in the field of supply chain risk management. [33] defined it as "the susceptibility to risks". According to [5] and [38] each supply chain organization is "exposed" to unforeseen disruptive events caused by unexpected changes in its environment. These changes are referred to them as potential risk factors. e.g. political instability, strikes which have been considered as a potential risk factors. Hence, researchers defined the risk exposure as "the measure of the sensitivity of a firm's to fluctuations in the relevant risk factor that could affect a firms continuity"[36-37]. The term exposure is used to indicate those elements-at-risk that are subject to potential losses. Then, exposure describes the characteristics of an asset or a supply chain that make it vulnerable to the negative effects of a disruptive events [22]. Following the work of [41], supply chain risk occurrence is a combination of an action (disruptive events) and condition (SC characteristics) that could leads to negative impacts[15]. The authors [15] considers that all type of risk are triggered by a disruptive events (which have been considered as the active component of risk) and a set of conditions (supply chain characteristics). Without these two previous elements or dimensions, risk doesn't exist. Following this logic of thinking, we model Risk probability as a function of exposure factors and the occurrence of disruptive events (see Fig.1).

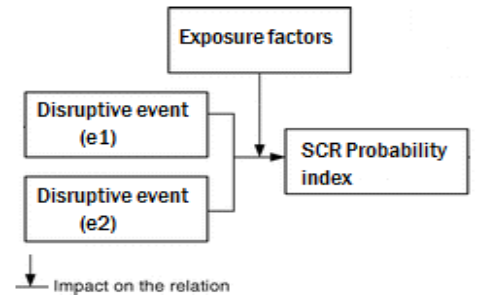

Causal pathway

How a disruptive event may reach $\mathrm{SC}$ asset? $\underline{P(S C R)}=\mathbf{f}$ (exposure factors, disruptive events)

Fig. 1. Proposed model. 
Supply chain risk occurrence is not only a conceptual model as it had been described in Fig.1. It can also be actually calculated. A general risk function is introduced to compute the risk occurrence probability as a function of :

1. The occurrence of disruptive events reflects the number of times a particular type of event happens over a period of time. It can be modeled using a Poisson distribution with the assumption that events are not correlated, as follow :

$$
p(k)=P(X=k)=\frac{\lambda^{k}}{k !} e^{-\lambda}
$$

where

\section{$\lambda$ is the number if occurrence per time period} $\underline{\mathbf{k}}$ is the disruptive event (under study)

2. The amount of exposure factors that characterize supply chain. [15] , [25] and [39] highlight that supply chain trends are considered as exposure factors that could leads to potential risks. [31] use Normal Accident Theory to investigate how supply chain trends leads to increase the level of exposure to risks. The results of their study demonstrate that certain supply chain practices comprise certain exposure factors that increase the probability of supply chain risk occurrence. Let us assume that there are (n) trends applied for company (j) where the relative importance weight for (i) managerial trend (tij) is measured by (wij). As the result, the total number of trends applied in company (j) is modeled by the equation (1). Each applied trend cause a set of exposure factors. As a result, potential exposure (PE) equation for a specific company (j) could be modelled as follow :

$$
\begin{gathered}
\mathrm{T}(\mathrm{j})=\sum_{i=0}^{n} \mathrm{w}(\mathrm{ij}) * \mathrm{t}(\mathrm{ij}) \quad \text { with } \mathbf{n}=7 \text { and } \mathbf{0} \leq \mathbf{w} \leq \mathbf{1} \\
\mathrm{EF}(\mathrm{i})=\left[\sum_{i=0}^{p} \mathrm{ef}(\mathrm{ki}) * \mathrm{t}(\mathrm{ki})\right] / \mathrm{p} \text { with } \mathbf{p}=7 \\
\mathrm{PE}(\mathrm{j})=\sum_{i=0}^{n} \mathrm{w}(\mathrm{ij}) *\left[\left(\sum_{i=0}^{p} \mathrm{ef}(\mathrm{ki}) * \mathrm{t}(\mathrm{ki})\right) / 7\right]
\end{gathered}
$$

3. As a result, the first equation need to be adjust it basing on this assumption, to compute the new occurrence probability of supply chain risk and will help understanding its causal pathway. To compute the new index, different scenarios need to be considered. A definition of a risk scenario includes a combination of a set of disruptive events and a selected number of exposure factors to determine the potential causal links between them. These scenarios will be defined basing on experts judgement and historical data and ranged between 0 (no risk) and 1(risk is occurring).

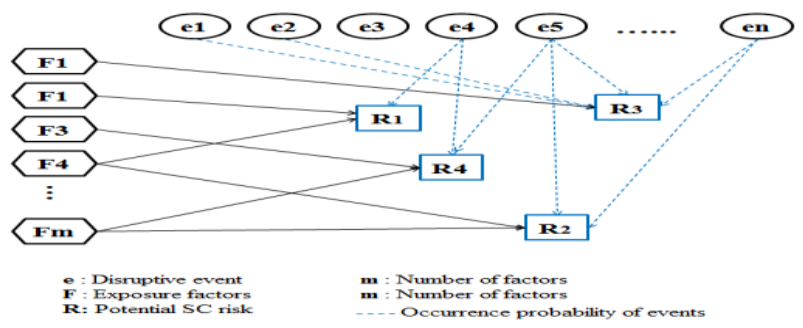

Fig. 2. Scenario Development. 
The result of described methodology is "a set of causal matrix and initial hypotheses about the structure of the causal chain of supply chain risks which must then be tested. The matrix can offer two forms of assistance in dealing with multifarious supply chain risks. Then the new probability occurrence for each risk could be then calculated as follow

$$
\mathbf{P}(\mathbf{x}=\mathbf{k}+\mathbf{P E})=\left(\frac{\mathbf{e}^{-(\mathrm{k}+\mathrm{PE})}}{\mathbf{k} !}\right)(\mathbf{k}+\mathbf{P E})^{\mathbf{k}}
$$

\section{Conclusion}

Managing supply chain risk is becomes today one of the most important issue for both academics and practitioners. However, to effective deal with risks and mitigate its impacts, a need to understand and to define the potential risks threaten supply chain. Probability approach has been widely used to address this need. Although that several researchers have emphasis the need to develop other alternatives that could taking into account the risk dimensions in side and the supply chain characteristic in other side. Trying to address the need, a new attempt has been developed basing in the exposure analysis. We present a first essay to quantify the probability of occurrence of supply chain risk considering the supply chain characteristics through the exposure analysis. The first step was to understand the measurement and the assessment approach of supply chain risks probability. Then in second step, the identification of the exposure factors was carried out. The results of this step has reveal that managerial trends applied increase the level of exposure to supply chain risks through a set of factors. These latter, combined with the probability of disruptive events are computed to develop a new risk probability index. The Poisson distribution was used in this research to quantify the occurrence probability of potential disruptive events. Then, we integrate an estimated exposure index into the calculated probability to give more accurate index of supply chain risks occurrence.

The developed approach is a work in progress. Future evaluation and experimental analysis are expected.

\section{References}

1. Supply Chain Resilience, 6th Annual Survey, Business Continuity Institute. Available at http://knowledge.zurich.com/supply-chain/supply-chain-resilience, 2014

2. Hallikas, J., and Lintukangas, K.: Purchasing and supply: An investigation of risk management performance. In: International Journal of Production Economics, vol. 171, part 4, pp. 487--494, 2016.

3. Ho, W., Zheng, T., Yildiz, H., and Talluri, S.: Supply chain risk management: a literature review. In: International Journal of Production Research, pp. 1--39, 2015.

4. Jury, G., and Matteo, K.: Supply risk management and competitive advantage: a misfit model. In: The International Journal of Logistics Management, Vol. 26, Issue. 3, pp. 459 -478, 2015. 
5. Peck, H.: Reconciling Supply Chain Vulnerability, risk and supply chain management. In: International Journal of Logistics: Research \& Applications, Vol. 9, No. 2, pp. 127--142, 2006.

6. Svensson, G.: A conceptual framework for the analysis of vulnerability in supply chains. In: International Journal of Physical Distribution \& Logistics Management, Vol. 30, No. 9, pp. 731--750, 2000.

7. Tang, C.S.: Robust strategies for mitigating supply chain disruptions. In: International Journal of Logistics: Research \& Applications, Vol. 9, No. 1, pp. 33--45, 2006.

8. Wagner, S.M., and Bode, C.: An empirical investigation into Supply Chain Vulnerability. In: Journal of Purchasing and Supply Management, Vol. 12, No. 6, pp. 301--312, 2006.

9. Wagner, S. M., and Neshat, N. (2012). A comparison of Supply Chain Vulnerability indices for different categories of firms. International Journal of Production Research, 50(11), 2877 $-2891,2012$.

10.Scholten, K., Sharkey, S, P., and Fynes, B.: Mitigation processes-antecedents for building supply chain resilience. In: Supply Chain Management: An International Journal, Vol.19, No.2, pp.211--228, 2014.

11. Pfohl, Hans-Christian, Philipp Gallus, and David Thomas. "Interpretive structural modeling of supply chain risks." International Journal of physical distribution \& logistics management 41.9 (2011): 839-859.

12. Heckmann, I. (2016.a). Towards Supply Chain Risk Analytics: Fundamentals, Simulation, Optimization. Springer.

13. Heckmann, I. (2016.b). Supply Chain Risk Analysis-Common Flaws, Core Areas, and Main Tasks. In Towards Supply Chain Risk Analytics (pp. 77-129). Springer

14. Heckmann, I., Comes, T., \& Nickel, S. (2015). A critical review on supply chain riskDefinition, measure and modeling. Omega, 52, 119-132.

15. Paulsson, U., Nilsson, C. H., Wandel, S.: Estimation of disruption risk exposure in supply chains. In: International Journal of Business Continuity and Risk Management, vol.2, $\mathrm{n}^{\circ} 1$, pp1--19 (2011)

16. Lahmar, A., Galasso, F., Chabchoub, H., and Lamothe, J.: Towards an Integrated Model of Supply Chain Risks: An Alignment Between Supply Chain Characteristics and Risk Dimensions. In: Risks and Resilience of Collaborative Networks, pp. 3--16, Springer International Publishing, 2015.

17. Ayyub, B. M., McGill, W. L., \& Kaminskiy, M. (2007). Critical Asset and Portfolio Risk Analysis: An All-Hazards Framework. Risk Analysis, 27(4), 789-801.

18. DuHadway, S., Carnovale, S., \& Hazen, B. (2017). Understanding risk management for intentional supply chain disruptions: risk detection, risk mitigation, and risk recovery. Annals of Operations Research, 1-20.

19.Handfield, R., \& McCormack, K. P. (Eds.). (2007). Supply chain risk management: minimizing disruptions in global sourcing. CRC press.

20. Christopher, M., Peck, H.: Building the Resilient Supply Chain. In: International Journal of Logistics Management, vol.15, $n^{\circ} 2$, pp.1--14 (2004)

21. Wagner, S. M., and Neshat, N. (2012). A comparison of Supply Chain Vulnerability indices for different categories of firms. International Journal of Production Research, 50(11), 2877$-2891,2012$.

22. Karningsih, P. D., Kayis, B., \& Kara, S. (2010, April). Development of SCRIS: a knowledge based system tool for assisting organizations in managing supply chain risks. In Advanced Information Networking and Applications Workshops (WAINA), 2010 IEEE 24th International Conference on (pp. 55-60). IEEE.

23. Heckmann, I., Nickel, S., \& Saldanha-da-Gama, F. (2016). The risk-aware multi-period capacitated plant location problem (CPLP-Risk). In Int Conf Inf Syst Log Supp Chain. 
24. Craighead, C. W., Blackhurst, J., Rungtusanatham, M. J., Handfield, R. B.: The severity of supply chain disruptions: design characteristics and mitigation capabilities. In: Decision Sciences, vol. 38, no 1, pp. 131--156 (2007)

25. Bode, C., \& Macdonald, J. R. (2016). Stages of Supply Chain Disruption Response: Direct, Constraining, and Mediating Factors for Impact Mitigation. Decision Sciences.

26. Bogataj, D., and Bogataj, M.: Measuring the supply chain risk and vulnerability in frequency space. In: International Journal of Production Economics, Vol.108, No.1, pp.291$-301,2007$.

27. Kamalahmadi, M., \& Parast, M. M. (2017). An assessment of supply chain disruption mitigation strategies. International Journal of Production Economics, 184, 210-230.

28. Gao, Y., Simchi-Levi, D., Teo, C. P., \& Yan, Z. (2016). Disruption Risk Mitigation in Supply Chains-The Risk Exposure Index Revisited.

29. Levner, E., \& Ptuskin, A. (2015). An entropy-based approach to identifying vulnerable components in a supply chain. International Journal of Production Research, 53(22), 68886902.

30. Tang, O., \& Musa, S. N. (2011). Identifying risk issues and research advancements in supply chain risk management. International journal of production economics, 133(1), 2534.

31. Snyder, L. V., Atan, Z., Peng, P., Rong, Y., Schmitt, A. J., \& Sinsoysal, B. (2016). OR/MS models for supply chain disruptions: A review. IIE Transactions, 48(2), 89-109.

32. Ponis, S. T., \& Ntalla, A. C. (2016). Supply Chain Risk Management Frameworks and Models: A Review. International Journal of Supply Chain Management, 5(4), 1-11.

33. Spekman, R. E. and Davis, E. W. (2004) Risky business: expanding the discussion on risk and the extended enterprise. International Journal of Physical Distribution \& Logistics Management,34, 414-433.

34. Chopra, S., \& Sodhi, M. S. (2014). Reducing the risk of supply chain disruptions. MIT Sloan management review, 55(3), 73

35. Zsidisin, G.A.: A Grounded Definition of Supply Risk. In: Journal of Purchasing and Supply Management, vol.9, pp. 217--224 (2003)

36. Hallikas, J., Karvonen, I., Pulkkinen, U., Virolainen, V. M., Tuominen, M..: Risk management processes in supplier networks. In: International Journal of Production Economics, vol. 90, no 1, pp. 47-58 (2004)

37. Svensson, G.: Dyadic vulnerability in companies' inbound and outbound logistics flows. In: International Journal of Logistics, Vol.5, No.1, pp.13--43, 2002.

38.Svensson, G.: Interactive vulnerability in buyer-seller relationships: a dyadic approach. In: International Journal of Physical Distribution \& Logistics Management, Vol.34, No.8, pp. 662--682; 2004.

39. Jüttner, U., Peck, H., \& Christopher, M. (2003). Supply chain risk management: Outlining an agenda for future research. International Journal of Logistics: Research and Applications, 6(4), 197-210.

40. Lahmar, et al.(2016) " Development of supply chain vulnerability drivers interrelationships model using interpretive structural modeling" Proceedings of the 28th International Business Information Management Association Conference - Vision 2020: Innovation Management, Development Sustainability, and Competitive Economic Growth , pp. 2675 - 2689 .

41. World Economic Forum : "A Global Risk Network Report2017". Geneva: World Economic Forum; 2017

42. Resilinc Company, : EventWatch ${ }^{\circledR}$ Supply Chain Disruption Annual Report"; 2016

43. Peck, H.: Drivers of supply chain vulnerability: an integrated framework. In: International journal of physical distribution and logistics management, Vol.35, No.4, pp.210--232, 2005. 